\title{
Article \\ Numerical Evaluation of Early-Age Crack Induction in Continuously Reinforced Concrete Pavement with Different Saw-Cut Dimensions Subjected to External Varying Temperature Field
}

\author{
Muhammad Kashif*(D), Ahsan Naseem (D), Nouman Iqbal ${ }^{D}$, Pieter De Winne and Hans De Backer ${ }^{D}$ \\ Department of Civil Engineering, Ghent University, Technologiepark 60, Zwijnaarde, B-9052 Ghent, Belgium; \\ ahsan.naseem@ugent.be (A.N.); nouman.iqbal@ugent.be (N.I.); p.dewinne@ugent.be (P.D.W.); \\ hans.debacker@ugent.be (H.D.B.) \\ * Correspondence: muhammad.kashif@ugent.be
}

Citation: Kashif, M.; Naseem, A.; Iqbal, N.; Winne, P.D.; De Backer, H. Numerical Evaluation of Early-Age Crack Induction in Continuously Reinforced Concrete Pavement with Different SawCut Dimensions Subjected to External Varying Temperature Field. Appl. Sci. 2021, 11, 42. https://dx.doi.org/ 10.3390/app11010042

Received: 18 November 2020 Accepted: 18 December 2020 Published: 23 December 2020

Publisher's Note: MDPI stays neutral with regard to jurisdictional claims in published maps and institutional affiliations.

Copyright: $\odot 2020$ by the authors. Licensee MDPI, Basel, Switzerland. This article is an open access article distributed under the terms and conditions of the Creative Commons Attribution (CC BY) license (https: / / creativecommons.org/ licenses/by/4.0/).

\begin{abstract}
Since 1970, continuously reinforced concrete pavements have been used in Belgium. The standard design concept for $\mathrm{CRCP}$ has been modified through several changes made in the design parameters to eliminate the cluster of closely spaced crack patterns, since these crack patterns lead to the development of spalling and punch-out distresses in CRCPs. Despite adjusting the longitudinal reinforcement ratio, slab thickness, and addition of asphalt interlayer, the narrowly spaced cracks could not be effectively removed. The application of transverse partial surface saw-cuts significantly reduced the probability of randomly occurring cracks in the reconstruction project of the Motorway E313 in Herentals, Belgium. The field investigation has also indicated that the early-age crack induction in CRCP is quite susceptible to the saw-cut depth. Therefore, the present study aims to evaluate the effect of different depths and lengths of the partial surface saw-cut on the effectiveness of crack induction in CRCP under external varying temperature field. For this purpose, the FE software program DIANA 10.3 is used to develop the three dimensional finite element model of the active crack control CRCP segment. The characteristics of early-age crack induction in terms of crack initiation and crack propagation obtained from the FE model are compared and discussed concerning the field observations of the crack development on the active crack control E313 test sections. Findings indicate that the deeper saw-cut with longer cut-lengths could be a more effective attempt to induce the cracks in CRCP in desirable distributions to decrease the risk of spalling and punch-out distresses in the long-term performance of CRCP. These findings could be used as guidance to select the appropriate depth and length of saw-cut for active crack control sections of CRCP in Belgium.
\end{abstract}

Keywords: early-age crack induction; saw-cut depth; saw-cut length; continuously reinforced concrete pavement; finite element analysis

\section{Introduction}

Continuously reinforced concrete pavement $(\mathrm{CRCP})$ is an excellent rigid pavement solution for high priority routes with long-life performance and minimum maintenance [1-6]. In this type of pavement structure, the continuous longitudinal steel bars are provided throughout the entire length of the concrete slab without any transverse joints to hold the randomly occurring transverse cracks tightly together which ensures that the pavement acts as a continuous system [7]. Therefore, CRCP's performance is mainly dependent on the development of transverse crack patterns [2,8-11].

Inspired by the experience of CRCP in the United States, Belgium has been using CRCP to build the highly trafficked roadways since 1970. The proponents of Belgium's CRCP cite a long-lasting pavement solution with minimum overall lifecycle cost. However, 
the cluster formation in the transverse crack patterns could not be effectively eliminated. Regular field observations of the crack developments on CRCPs in Belgium indicate the low mean crack spacing of transverse crack patterns with a high percentage of cluster crack formation $[5,9,12-15]$. Large-scale field and laboratory testing of various pavement sections in the United States have revealed that the majority of punch-out distress occurs in CRCP that exhibits a transverse crack pattern of spacing ranging between $0.3 \mathrm{~m}$ and $0.6 \mathrm{~m}$ and especially in the narrowly spaced crack patterns [16,17].

Despite the crack cluster formation, Belgium's CRCP following the current standard design concept exhibits excellence performance. However, the risk of punch-out distress is still pertaining due to the development of a short-spaced crack pattern and some CRCP sections have also experienced punch-out in the outer lane of the pavement slab. Therefore, it is essential to optimize the crack spacing pattern in CRCP. The design parameters have been modified in order to eliminate the non-uniformity of the crack pattern. For this purpose, several changes have been made in the standard CRCP design and constructions in Belgium by varying the longitudinal reinforcement ratio, depth of steel layer, the thickness of the concrete slab, concrete mix properties, presence of an asphalt interlayer, and surface finishing, as demonstrated in Table $1[12,14]$. Field observations indicated that the desirable average crack spacing and crack width of fully developed transverse crack pattern could be obtained by these attempts, but it has been challenging to eliminate the crack cluster formation by just adjusting the amount of longitudinal reinforcement, due to the heterogeneous nature of concrete properties, deficiencies in construction process and environmental factors, which could not be effectively controlled by the contractor [5,6,9-17].

Table 1. Overview of design concepts for CRCP in Belgium.

\begin{tabular}{cccc}
\hline Design Concept & Concept 1 & Concept 2 & Concept 3 \\
\hline Time span & $1970-1981$ & $1981-1995$ & $1995-$ onwards \\
Longitudinal reinforcement & $0.85 \%(\varnothing 18 @ 150 \mathrm{~mm})$ & $0.67 \%(\varnothing 16 @ 150 \mathrm{~mm})$ & $0.75 \%(\varnothing 20 @ 170 \mathrm{~mm})$ \\
Cover depth & $60 \mathrm{~mm}$ & $90 \mathrm{~mm}$ & $80 \mathrm{~mm}$ \\
Slab thickness & $200 \mathrm{~mm}$ & $200 \mathrm{~mm}$ & $230 / 250 \mathrm{~mm}$ \\
Asphalt Interlayer & Yes, $60 \mathrm{~mm}$ & No & Yes, $50 \mathrm{~mm}$ \\
\hline
\end{tabular}

Another method usually employed to reduce the non-uniformly spaced cracks is active crack control. Initially, it has been extensively used for the crack induction in rigid pavement structures such as jointed plain concrete pavements (JPCPs). For the very first time, the full-scale test sections of CRCP with active crack control method were constructed in the United States $[2,8,18-21]$. It was reported that this crack induction method could effectively be employed to induce the regular spaced transverse crack pattern in CRCP. This method has been used either in form of automated tape insertion or the transverse saw-cuts along the width of the pavement. In the United States, the active crack control technique is applied to CRCP by either automated tape insertion or transverse saw-cut through the whole width of a concrete slab. The tape insertion into fresh concrete often poses difficulty in the construction process. While the thorough saw-cut along the entire width of pavement causes the spalling over the pavement surface, which often reduces the ride comfort and also increases the maintenance cost.

Owing to these limitations of active crack control in the United States, the concept of partial surface transverse saw-cuts was introduced for CRCPs in Belgium [14]. In this method, the partial surface saw-cuts were made on the outer side of the concrete slab perpendicular to the axis of the road within 16 to $24 \mathrm{~h}$ after the concrete placement by using a cutting disk. The regular field crack surveys revealed the susceptibility of early-age cracking induction in CRCPs to the saw-cut dimensions. In advance of costly field trials, numerical modeling could be a useful technique to evaluate the effect of different saw-cut dimensions on early-cracking induction in CRCP under external varying temperature conditions.

Present study develops the three-dimensional (3D) finite element (FE) model of CRCP segment for evaluating the effect of partial surface saw-cut on the early-age crack induc- 
tion in CRCP under external varying temperature field. Field observations of cracking characteristics of CRCPs with and without partial saw-cuts in Belgium are used to validate the results obtained from FE analysis. Moreover, the parametric study has been conducted to evaluate the effect of different depths and lengths of partial surface saw-cut on the effectiveness of crack initiation and crack propagation in CRCP.

\section{Cracking Characteristics of CRCPs in Belgium}

Characterization of CRCP's long-term performance is largely determined by the early-age cracks, hence crack induction and patterns are of interest for most highway departments [12]. The elimination of randomness in an early-age crack pattern of CRCP has been a point of research interest among the researchers for a long time. Different crack induction methodologies such as metallic tape insertion and transverse saw-cutting have been tried to induce uniform crack pattern over the designated locations in CRCP. In Belgium, the transverse partial surface saw-cuts at one of the outer edges of the pavement concrete slab within $24 \mathrm{~h}$ after concrete pouring is used as the most effective crack induction method for the crack induction in CRCPs. This crack induction method was first introduced during the construction of $\mathrm{CRCP}$ sections in the reconstruction project of the Motorway E313 in Belgium. The transverse saw-cuts were made on the outer lane of the pavement within $24 \mathrm{~h}$ after the concrete placement. Two saw-cut depths of $60 \mathrm{~mm}$ and $30 \mathrm{~mm}$ were selected for crack development on CRCP test sections. Crack spacing surveys were conducted on the test sections just after the concrete placement without considering the effect of traffic loading on crack development. To evaluate the effectiveness of this crack induction method to induce the cracks from the desired locations of the concrete slab, the observed crack patterns of these test sections were compared with those of recently constructed CRCP sections without partial surface saw-cuts on the Motorway E17 in Belgium. The composition and properties of the concrete used in the CRCP section along with the instrumentation used are reported in the experimental study [12].

The survey results of the crack developments on the E313 sections with different saw-cut depths are illustrated in Table 2. For the CRCP section with a deeper saw-cut depth $(60 \mathrm{~mm})$, all the observed cracks were initiated from saw-cuts during first four days as shown in Figure 1 [22]. After a period of about two months, the deeper saw-cut section exhibited $78.6 \%$ of cracks over the saw-cuts. While in case of the section with $30 \mathrm{~mm}$ sawcut depth, this valued reduced to $56.5 \%$. It shows that the deeper saw-cut is more effective than the shallower saw-cut in inducing the cracks over the designated locations (tips of saw-cuts) in CRCP [22]. These field observations indicate that the partial surface saw-cuts can effectively induce the cracks within the first two months after the concrete placement. Even in the later age of CRCP, this crack induction method still played an effective role in inducing new cracks as demonstrated in Table 2. The test section with deeper saw-cuts exhibited the higher percentage of crack initiation at the notches in comparison to the test section with shallower saw-cuts, as depicted in Table 2.

Figure 2 demonstrates the cumulative crack spacing distribution of the crack pattern on the CRCP sections of the Motorway E313 and E17. It can clearly be observed that the section with $60 \mathrm{~mm}$ depth saw-cut illustrated a favorable crack spacing distribution than the section with $30 \mathrm{~mm}$ depth saw-cut and the section on the E17 [12,13,22]. The section with $60 \mathrm{~mm}$ depth saw-cut exhibited only $13.3 \%$ of total crack spaced less than $0.6 \mathrm{~m}$ (closely spaced cracks) and more than $74.3 \%$ of cracks within the desirable crack spacing range of $0.6 \mathrm{~m}$ to $2.4 \mathrm{~m}$ in Belgium. For the section on the E17, about $50 \%$ of cracks were spaced less than $0.6 \mathrm{~m}$, and only $27.6 \%$ of total cracks within desirable range $(0.6 \mathrm{~m}-2.4 \mathrm{~m})$ were observed. This finding indicates that the $60 \mathrm{~mm}$ saw-cut section has a better crack pattern than the $30 \mathrm{~mm}$ saw-cut section and the section without saw-cuts on E17. Based on these field observations, it may be concluded that the crack induction in CRCP is quite susceptible to the saw-cut depth. Therefore, the present study aims to evaluate the susceptibility of crack induction in CRCP to different saw-cut depths and saw-cut lengths. 
Table 2. Crack survey data on the 313 test sections [12,22].

\begin{tabular}{|c|c|c|c|c|c|c|c|c|c|c|}
\hline \multirow{2}{*}{$\begin{array}{c}\text { Test } \\
\text { Section }\end{array}$} & \multirow{2}{*}{$\begin{array}{l}\text { Length } \\
\text { (m) }\end{array}$} & \multirow{2}{*}{ Age (Days) } & \multirow{2}{*}{$\begin{array}{c}\text { No. of } \\
\text { Notches (N1) }\end{array}$} & \multirow{2}{*}{$\begin{array}{l}\text { No. of Cracks } \\
\text { (N2) }\end{array}$} & \multirow{2}{*}{$\begin{array}{l}\text { No. of Cracks } \\
\text { at Notches (N3) }\end{array}$} & \multirow{2}{*}{$\begin{array}{c}\text { Effectiveness of } \\
\text { Notches N3/N1 (\%) }\end{array}$} & \multicolumn{4}{|c|}{ Percentage of Cracks in Category by Distance to Nearest Notch (m) } \\
\hline & & & & & & & 0 & $0-0.2$ & $0.2-0.4$ & $0.4-0.6$ \\
\hline \multirow{4}{*}{$60 \mathrm{~mm}$} & 1100 & 4 & 897 & 193 & 191 & 21.3 & 98.9 & 0 & 0 & 1.1 \\
\hline & 1100 & 65 & 897 & 664 & 555 & 61.9 & 83.5 & 2.4 & 7.7 & 6.4 \\
\hline & 1100 & 204 & 897 & 762 & 597 & 66.6 & 78.4 & 3.8 & 9.8 & 8.0 \\
\hline & 1100 & 378 & 897 & 775 & 606 & 67.6 & 78.2 & 3.8 & 9.9 & 8.1 \\
\hline \multirow{3}{*}{$30 \mathrm{~mm}$} & 500 & 123 & 422 & 417 & 245 & 58.1 & 58.7 & 9.4 & 15.9 & 16.0 \\
\hline & 500 & 262 & 422 & 497 & 281 & 66.5 & 56.5 & 8.7 & 17.5 & 17.3 \\
\hline & 500 & 436 & 422 & 502 & 285 & 67.5 & 56.8 & 8.6 & 17.3 & 17.3 \\
\hline
\end{tabular}




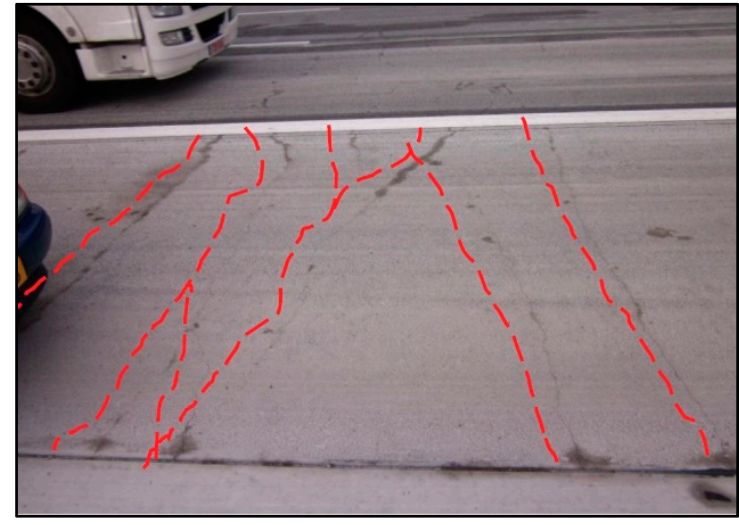

(a)

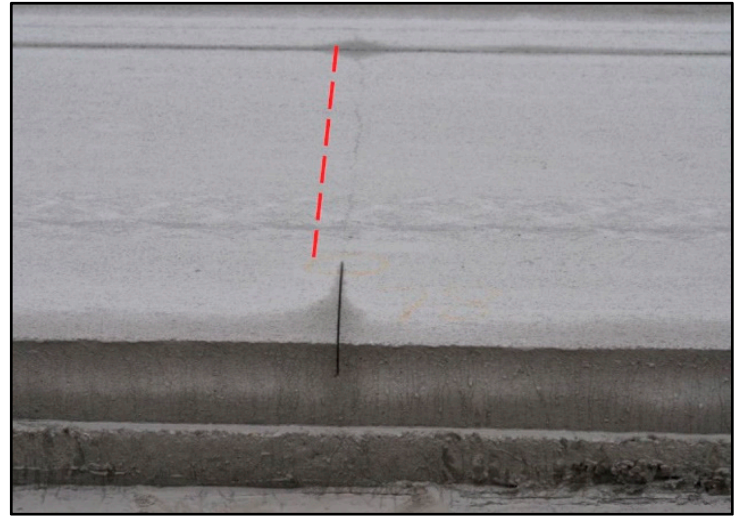

(b)

Figure 1. Development of crack pattern (a) E17 section (b) E313 section.

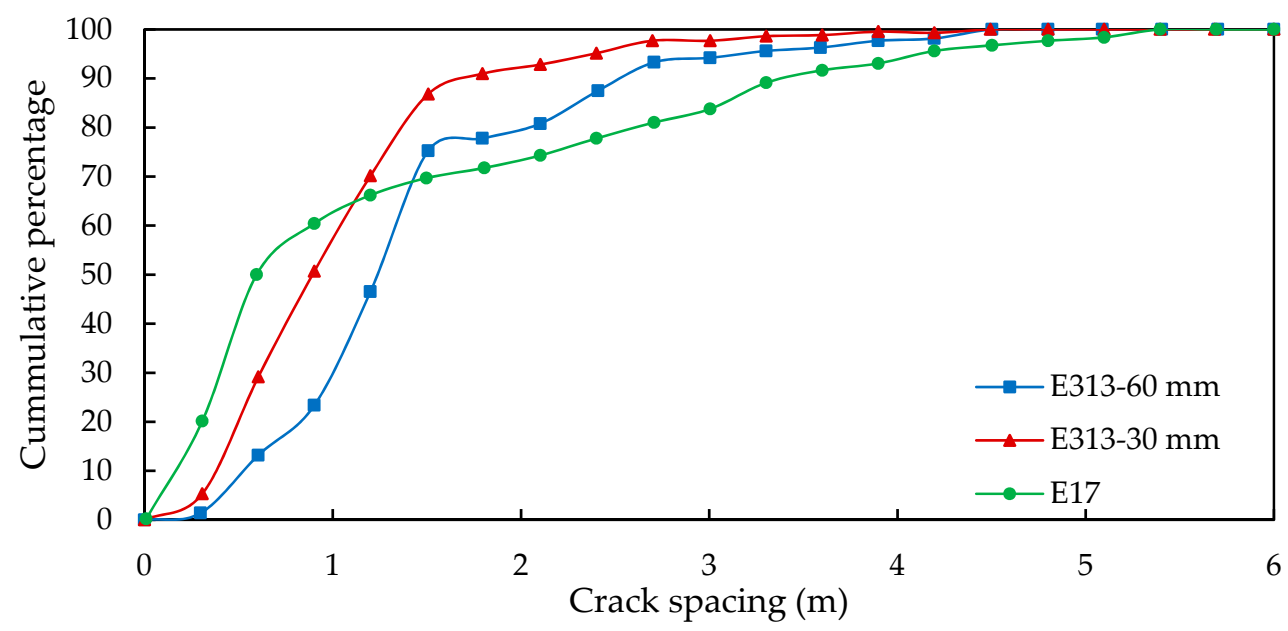

Figure 2. Comparison of cumulative crack spacing distribution.

\section{Finite Element Simulation of the CRCP Segment}

The FE program simulates the heat of hydration and the temperature gradient based on the degree of reaction with respect to the time. The simulation of early age crack induction in CRCP is carried out by using the FE program DIANA 10.3. A 3D FE model of the CRCP segment with a $60 \mathrm{~mm}$ deeper saw-cut as used on the E313 section is developed to study the early-age crack induction under the external varying temperature field. The feature of staggered structural-flow analysis in the DIANA program is used to study the development of temperature gradient calculated by transient heat flow analysis and stress computation by non-linear structural analysis. The evolution of concrete mechanical properties such as compressive strength, tensile strength and modulus of elasticity with time are incorporated in the FE model in accordance with the Euro-code 2 EN 1992-1-1 concrete material model available in the DIANA program [23].

\subsection{Geometry Configuration of the CRCP Segment}

In accordance with the current standard CRCP practice in Belgium, the partial surface saw-cuts at an interval of $1200 \mathrm{~mm}$ are sawn over the outer side of the concrete slab. A $50 \mathrm{~mm}$ thick asphalt interlayer is provided in between the $250 \mathrm{~mm}$ thick CRCP slab and $200 \mathrm{~mm}$ lean concrete base to avoid the direct contact of a concrete slab with the base. The $60 \mathrm{~mm}$ deeper saw-cut with $400 \mathrm{~mm}$ length and $4 \mathrm{~mm}$ width as used in the E313 test section is considered in the development of the reference 3D FE model of the CRCP segment. The longitudinal reinforcing steel bar of $20 \mathrm{~mm}$ diameter is placed at a spacing of $170 \mathrm{~mm}$ from 
the center of bars throughout the length of the pavement slab. The position of longitudinal reinforcement is taken $80 \mathrm{~mm}$ (from the center of bars) from the pavement surface. The $12 \mathrm{~mm}$ diameter transverse reinforcing steel bars are placed at a spacing of $600 \mathrm{~mm}$ from the center of bars across the width $[5,6,9,12-14,22,24,25]$.

CRCP behaves symmetrically with respect to the center of the two consecutive transverse cracks and the pavement lane under environmental loading [26-29]. Therefore, one-half of the concrete slab on either side of saw-cuts and another half of the pavement lane are taken into account by considering the appropriate boundary conditions. Due to symmetric conditions, the $2400-\mathrm{mm}$ long and $1800-\mathrm{mm}$ wide CRCP segment is considered in the present study. The assumed geometry configurations of the CRCP segment are shown in Figure 3.

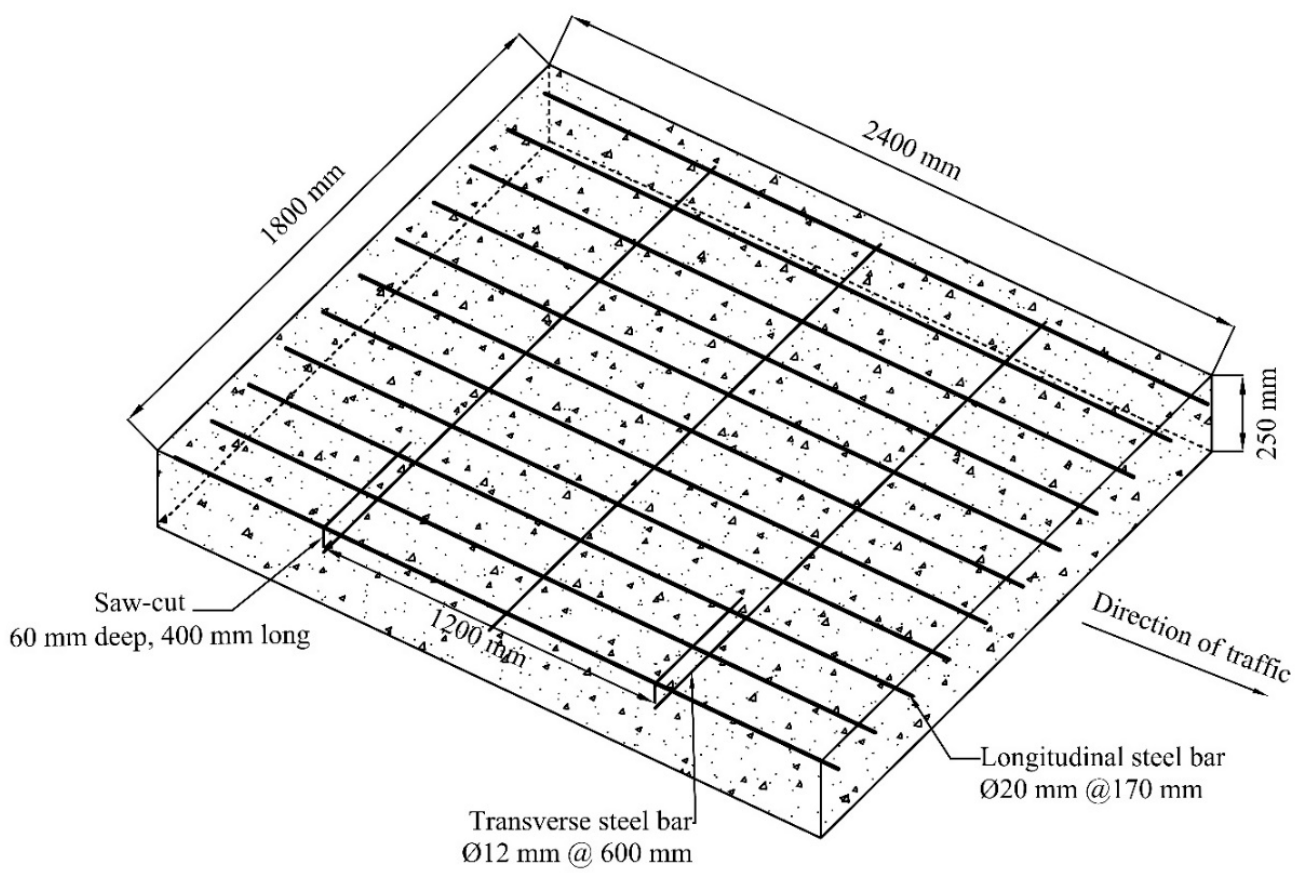

Figure 3. Geometry configuration of the CRCP segment.

\subsection{Thermo-Mechanical Properties}

Young hardening of concrete with total strain crack model in accordance with the Euro-code 2 EN 1992-1-1 model available in Diana FE program is used to simulate the early-age crack development in the CRCP segment under external varying temperature field [23]. The concrete class C40/50 is normally used in the construction of CRCP's in Belgium [12]. The thermal-mechanical parameters used in the FE analysis are demonstrated in Table 3. The specific heat parameter refers to the capacity of concrete to store heat. The value of specific heat capacity of concrete is taken as $2.87 \times 106 \mathrm{~J} / \mathrm{m}^{3}{ }^{\circ} \mathrm{C}$ based on previous studies [23,30-32].

Table 3. Thermo-mechanical parameters used in the FE model.

\begin{tabular}{cc} 
Concrete class & $\mathrm{C} 40 / 50$ \\
Aggregate type & Limestone \\
Coefficient of thermal expansion of concrete $\left(1 /{ }^{\circ} \mathrm{C}\right)$ & $10.0 \times 10^{-6}$ \\
Concrete thermal conductivity $\left(\mathrm{W} / \mathrm{m}^{\circ} \mathrm{C}\right)$ & 2.7 \\
Concrete volumetric heat specific capacity $\left(\mathrm{J} / \mathrm{m}^{3}{ }^{\circ} \mathrm{C}\right)$ & $2.87 \times 10^{6}$ \\
Convection-radiation coefficient between concrete and air $\left(\mathrm{W} / \mathrm{m}^{2}{ }^{\circ} \mathrm{C}\right)$ & 7.55 \\
\hline
\end{tabular}

The thermal conductivity of concrete determines the amount of heat transfer through conduction. Therefore, it is considered as an important factor in modeling the temperature 
gradients in early age concrete [33]. The constant value of thermal conductivity is assumed to be $2.7 \mathrm{~W} / \mathrm{m}^{\circ} \mathrm{C}[12,26,30]$. Owing to the difficulties in accurately determining the earlyage thermal properties of concrete, constant values have been used in the present study. The coefficient of thermal expansion (CTE) is a key parameter that provides a measure of volumetric changes in a material at varying temperatures. The CTE of concrete is affected significantly by the aggregate, which makes up $70 \%$ to $85 \%$ of the total solid volume of the concrete. It depends on the type of aggregate and its mineralogical composition, because of the large differences in the thermal properties of various types of aggregates $[34,35]$. Experimental investigations have revealed that the CTE of concrete remains constant after the final setting $[12,32,33]$. Therefore, a constant value of CTE as illustrated in Table 3 is used in the present study.

The type of cement has a dominant influence on the early-age cracking of concrete. The blast furnace slag cement (CEM III) is very often used for the construction of CRCPs in Belgium because of its low heat release, low permeability, and good durability [36]. The heat of hydration model valid for blast furnace slag cement is used to define the heat development in terms of adiabatic heat curve [37]. The development of mechanical properties (tensile strength, compressive strength, and elastic modulus) with respect to time are formulated as a function of the degree of reaction in accordance with the Eurocode 2 EN 1992-1-1 model code [23]. Input parameters for Euro-code 2 EN 1992-1-1 creep and shrinkage model are illustrated in Table 4.

Table 4. Input parameter for Euro-code 2 EN 1992-1-1creep and shrinkage model.

\begin{tabular}{cc}
\hline Input Parameters & Value \\
\hline Ambient temperature $\left({ }^{\circ} \mathrm{C}\right)$ & 20 \\
Notional size $(\mathrm{mm})$ & 439 \\
Relative humidity $(\%)$ & 80 \\
Curing age (Days) & 3 \\
\hline
\end{tabular}

Reinforcing steel bars are modeled as embedded reinforcement with a young modulus of $200 \mathrm{GPa}$ and yield strength of $500 \mathrm{MPa}$. The constitutive behavior of reinforcement is defined as elastoplastic with no hardening. Young modulus of and yield strength of steel. In embedded reinforcement, the perfect-bonding contact with zero bond-slip is considered between the reinforcing bars and concrete for the smooth convergence of the FE analysis [38-40].

\subsection{Boundary Conditions}

The boundary conditions of the CRCP segment are defined with respect to the thermal and structural problems. The bottom face of the concrete slab is restrained vertically by assuming a stiffer ground base layer below the concrete slab. The concrete slab is restrained in both the Y-Z planes and the symmetrical inner X-Z plane, however, the outer $X-Z$ plane on the saw-cut side is free. This translates that the concrete can contract, but it cannot expand because of the infinite surrounding concrete. The interface contact surface between the bottom of the concrete slab and ground base is modeled using a nonlinear elastic friction model [41].

For the thermal analysis, the top and outer edge faces of the concrete slab are directly exposed to the external varying temperature field as illustrated in Figure 4. For the potential heat flow, the convective interface boundary elements are taken into account for heat transfer through concrete and the external environment. The heat transfer coefficient is taken as $7.5 \mathrm{~W} / \mathrm{m}^{2}{ }^{\circ} \mathrm{C}$ from the literature $[35,42-44]$. The boundary conditions of the 3D FE model are illustrated in Figure 5. 


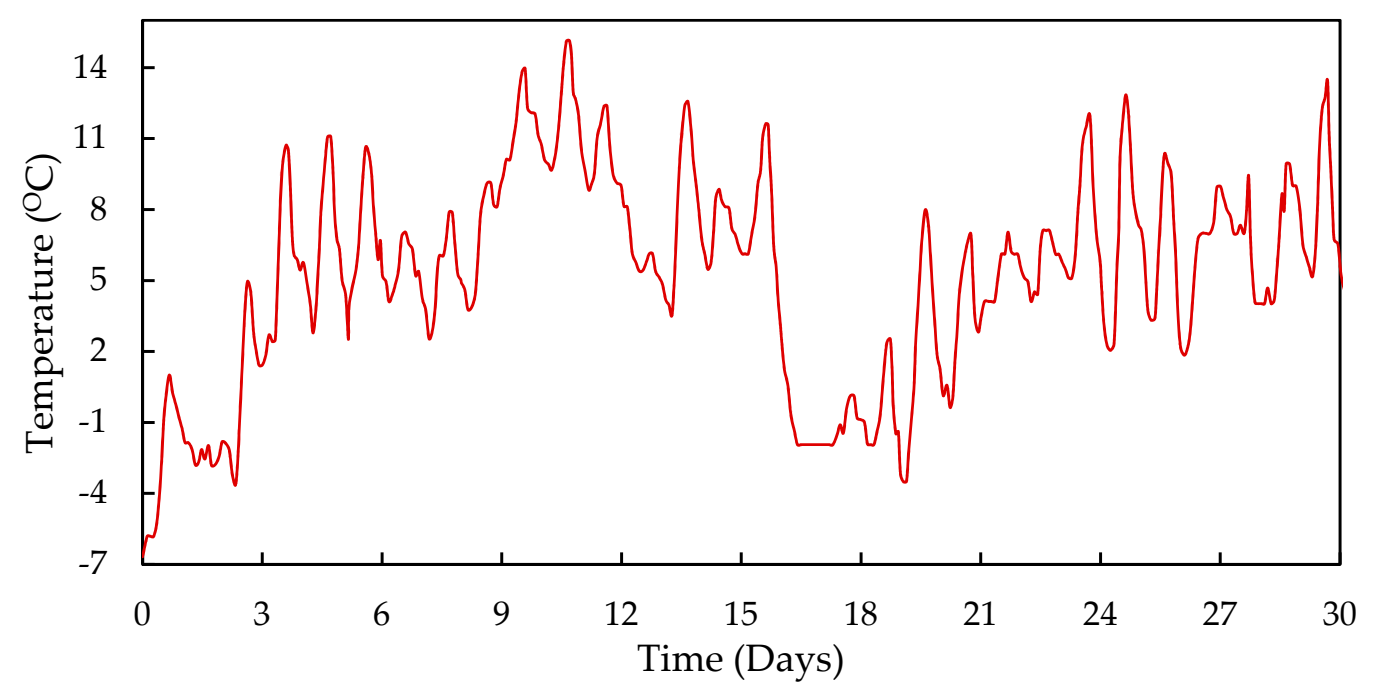

Figure 4. External varying temperature field.

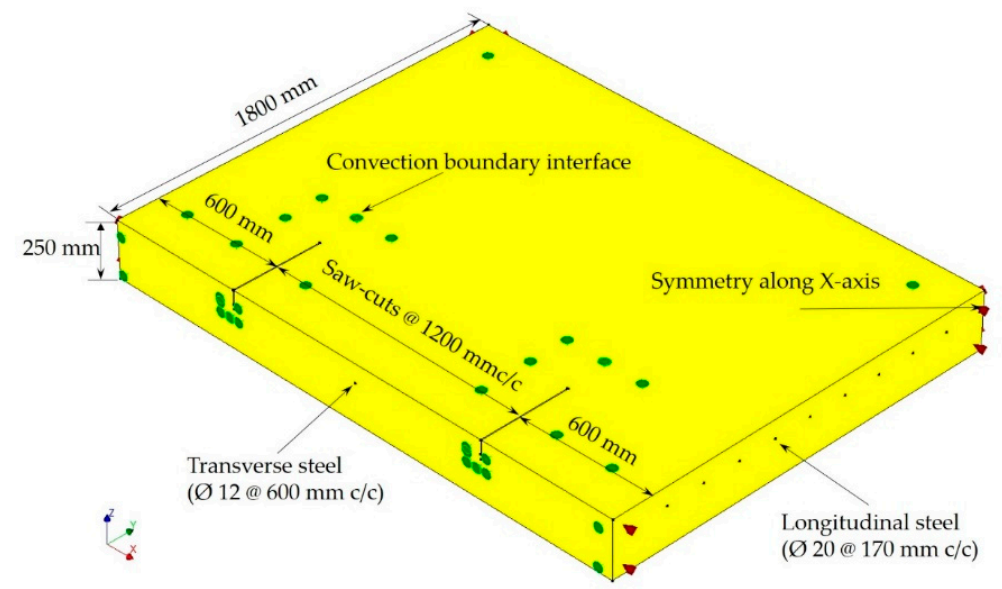

(a)

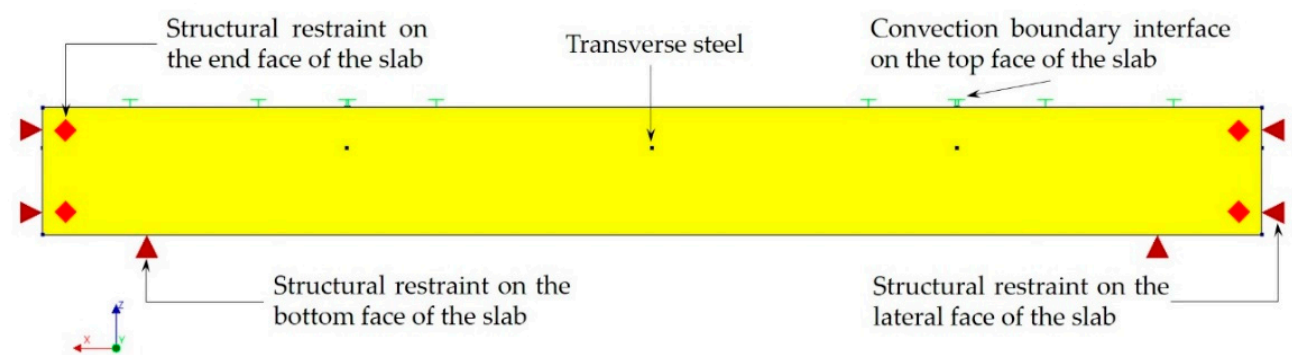

(b)

Figure 5. Boundary conditions of the 3D FE model: (a) Thermal boundary conditions; (b) Structural boundary conditions.

For the crack induction in CRCP under varying temperature field, the staggered structural-flow analysis is carried out in two parts. The first part of the analysis covers the transformation of the structural elements into the flow elements. In the second part, the temperature out of the flow element is used as thermal strains for the structural analysis. The self-weight of the CRCP segment is also considered as a gravity load in the analysis. Loading is applied in terms of small-time increments in order to avoid the convergence issues. 


\subsection{Elements Used in FE Simulation}

The upper and exterior edge faces of the CRCP segment as shown in Figure 5 which are directly exposed to the external environment, are modeled using a four-node isoparametric quadrilateral element (BQ4HT), which is specially used to define the convective interface boundaries in 3D heat flow analysis. The concrete is discretized by using a 20-node isoparametric solid brick element (CHX60). The interface between the concrete and ground base is modeled by an eight-node element (CQ481) with interface elements of zero-thickness. The accuracy of the FE analysis depends on the size and characteristics of the element in the mesh. The size of the element is taken as $30 \mathrm{~mm}$ based on the mesh sensitivity analysis.

\subsection{Type of Cracking Model Used in FE Simulation}

The smeared cracking approach has been used to simulate the cracking behavior of concrete. In this approach, the cracked material is treated as continuous, and the discontinuity of the displacement field caused by the crack is spread across the element by changing the concrete constitutive equation following crack development in the element. Cracking in concrete occurs when the tensile stress exceeds the tensile strength of concrete.

\section{Validation of FE Model}

The original intention of the saw-cuts in CRCP's is to induce cracks from the desired locations (saw-cut tips) which leads to the development of an improved cracking pattern (regular spaced cracks) [12,22]. The reference FE model, with the same configurations of the saw-cuts used in the E313 test section as discussed in Section 3.1, is developed to simulate the crack induction in CRCP. The maximum tensile stress occurs over the saw-cut tips in comparison to the rest of the concrete slab at the age of $81 \mathrm{~h}$ (3.37 days). The development of tensile stress against the tensile strength over the saw-cut tips along the length of pavement illustrated in Figure 6 indicates the crack induction from the saw-cut tips. Figures 7 and 8 demonstrate the crack strains (mapped cracking) represented by "Eknn", at the age of $91 \mathrm{~h}$ (3.7 days) and $144 \mathrm{~h}$ (6 days), respectively. It can clearly be observed in Figures 7 and 8 that cracks initiate exactly from the saw-cut tips and propagate along the width of pavement as observed during field observations on the E313 test section which is discussed above in Section 2. Moreover, the development of maximum stress in the 3rd longitudinal steel bar just ahead of saw-cut tips is demonstrated in Figure 9. The steel bar experiences the maximum stress exactly below the transverse crack induction. It indicates that the methodology and assumptions considered in the development of the reference FE model are appropriate for simulating the crack induction in CRCP.

Additionally, the FE model without partial surface saw-cuts is also developed to simulate the crack induction and the comparison is made with the field observation and the results obtained from the reference FE model with saw-cuts. As illustrated in Figure 1, a cluster of closely spaced cracks occurred on the E17 section without active crack control. The crack induction obtained from the FE model without active crack control is illustrated in Figure 10. It can clearly be seen that the same crack pattern is produced as monitored during the filed investigation on the E17 section. The FE model with and without saw-cuts produces the same crack induction as observed during field investigations on E313 and E17 sections. Therefore, it may be assumed that the developed FE model with proposed considerations for the crack induction in CRCP could be further used to optimize the saw-cut dimensions in advance of costly field trials which is the major interest of the present study. 


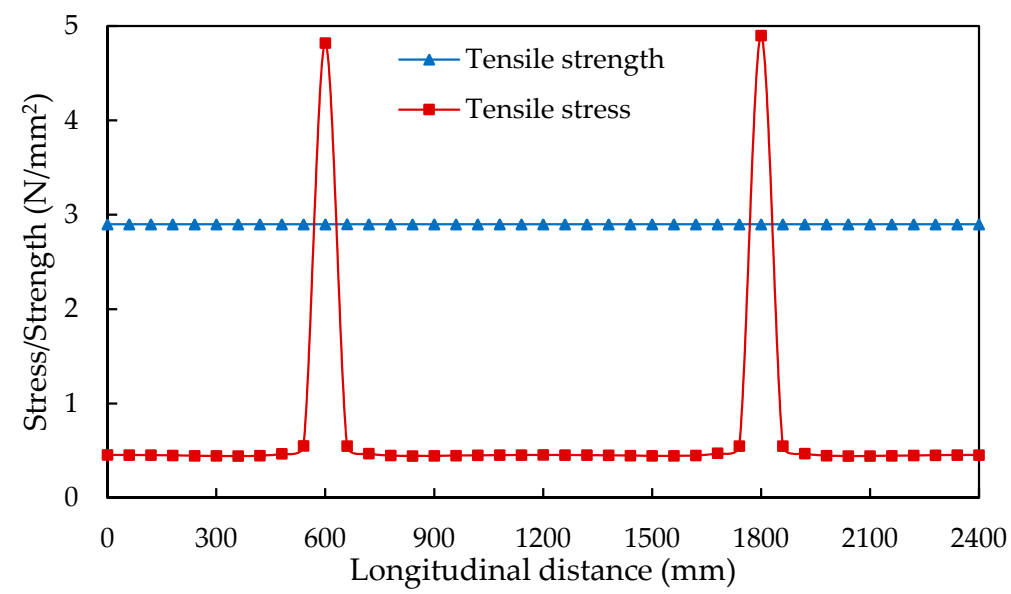

Figure 6. Development of maximum tensile stress against tensile strength over the saw-cut tips along the length of pavement.

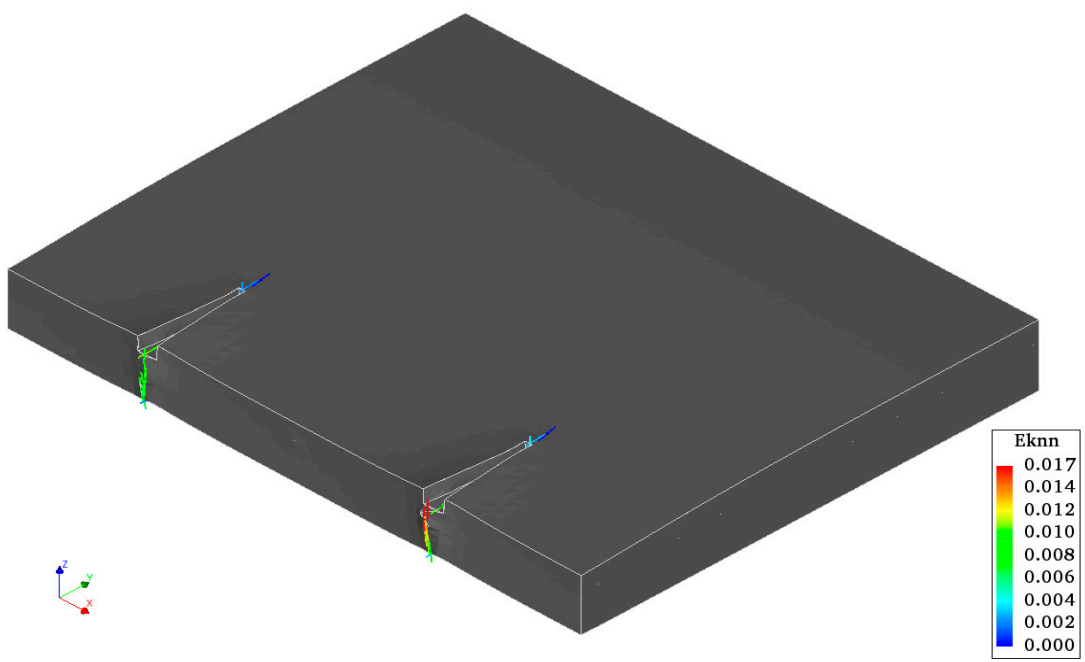

Figure 7. Crack initiation from the saw-cuts.

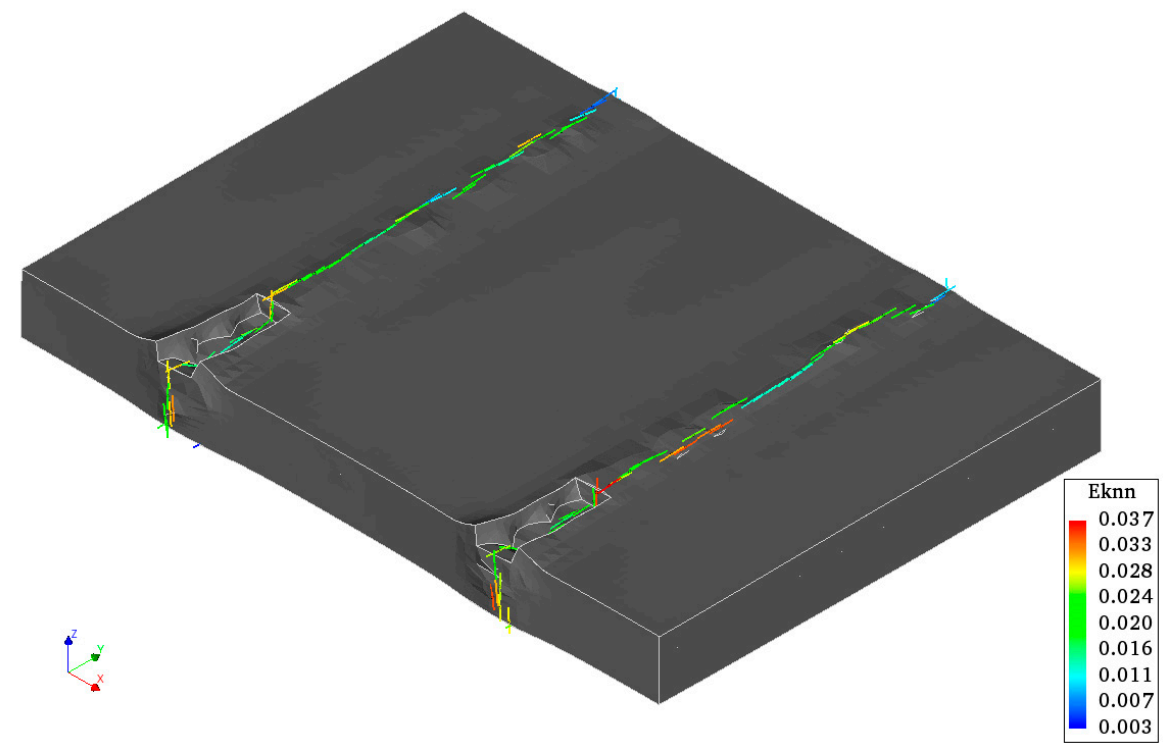

Figure 8. Crack propagation along the width of concrete slab. 


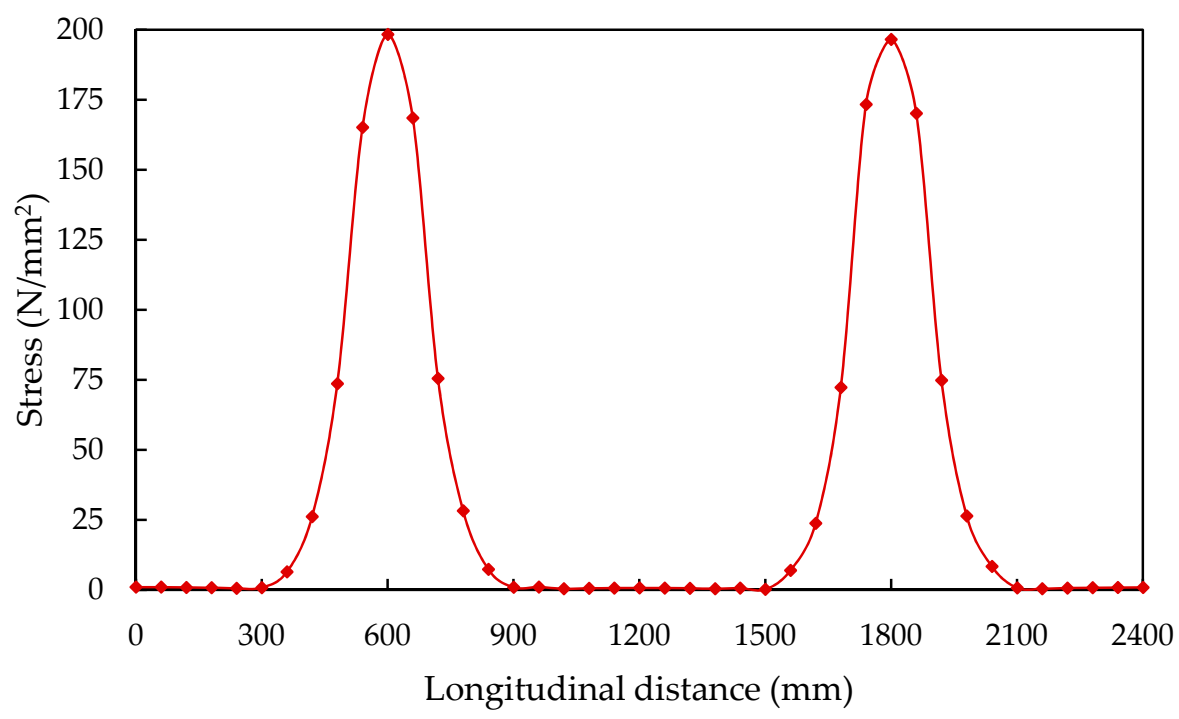

Figure 9. Stress variation in the longitudinal steel bar.

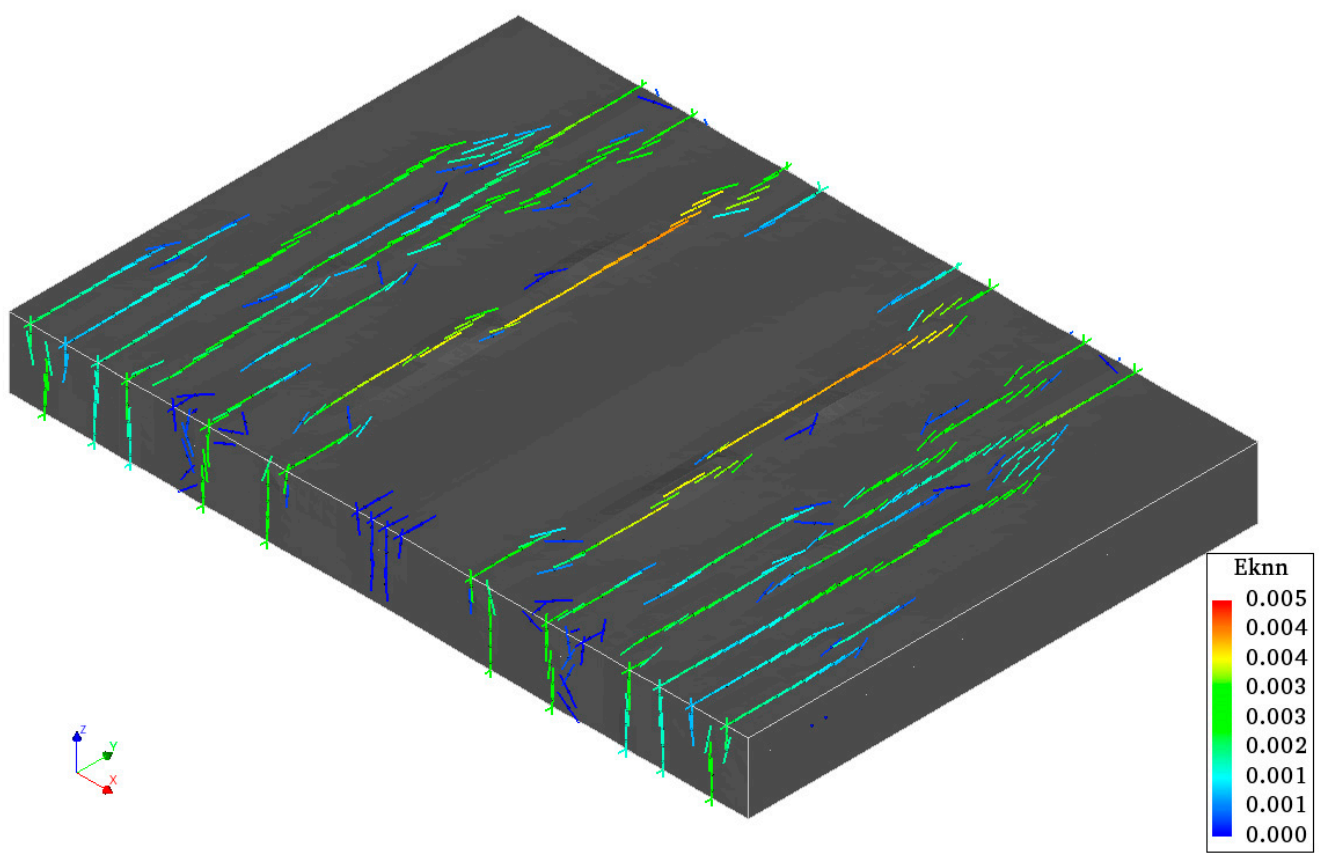

Figure 10. Development of the randomly occurring crack pattern in CRCP segment without active crack control.

\section{Parametric Study}

As discussed above, the crack induction in CRCP is susceptible to the saw-cut depth. Therefore, a parametric study is conducted to evaluate the effect of saw-cut depth on early-age crack induction. Three different saw-cut depths as demonstrated in Table 5 are considered in the present study. The development of maximum tensile stress over the saw-cut tips, steel stress variation in 3rd longitudinal steel bar, and crack strains are evaluated with respect to the type of saw-cut based on depth. The optimal dimensions of saw-cut are discussed based on the results obtained from the parametric study. 
Table 5. Type of saw-cut based on cut-depth.

\begin{tabular}{ccccc}
\hline No. & Saw-Cut Type & Depth, D $(\mathbf{m m})$ & Length, L (mm) & Width $(\mathbf{m m})$ \\
\hline 1 & Shallower & 20 & 400 & 4 \\
2 & Conventional & 40 & 400 & 4 \\
3 & Deeper & 60 & 400 & 4 \\
\hline
\end{tabular}

\subsection{Effect of Saw-Cut Depth on Early-Age Crack Induction}

$\mathrm{CRCP}$ is known for its random cracking at the early-age. The elimination of randomness in an early-age crack pattern of CRCP has been a point of research interest among the researchers for a long time. The previous field studies have revealed that the early-age behavior of CRCP significantly influences its long-term performance $[5,6,9,12-14,22]$. The primary factor affecting the development of early-age cracking in CRCP is the resistance to the change of length of the concrete slab [20]. In Belgium, the active crack control CRCP test sections exhibited the crack induction over the saw-cut tips which ultimately led to the development of a regular spaced crack pattern in comparison to the passive crack control sections.

The crack induction over the saw-cut tips is explained with respect to the development of maximum concrete tensile stress along the length of the concrete slab. As shown in Figure 11, among different saw-cuts, the deeper saw-cut exhibits the largest maximum concrete tensile stress by taking an advantage of deeper cut-depth into the concrete slab. Regular crack survey of active crack control E313 test sections revealed that there was a much more regular crack pattern in CRCP sections with deeper partial surface notches $[12,22]$. However, the potential risk of steel corrosion would be significantly increased when the saw-cut will be made deeper into the concrete slab as the steel is being placed at a depth of $80 \mathrm{~mm}$ from the pavement surface in accordance with the current design concept for CRCPs in Belgium. Preventive measures would be required to minimize the accumulation of dust particles and the water infiltration through the cracks into the steel of the pavement slab.

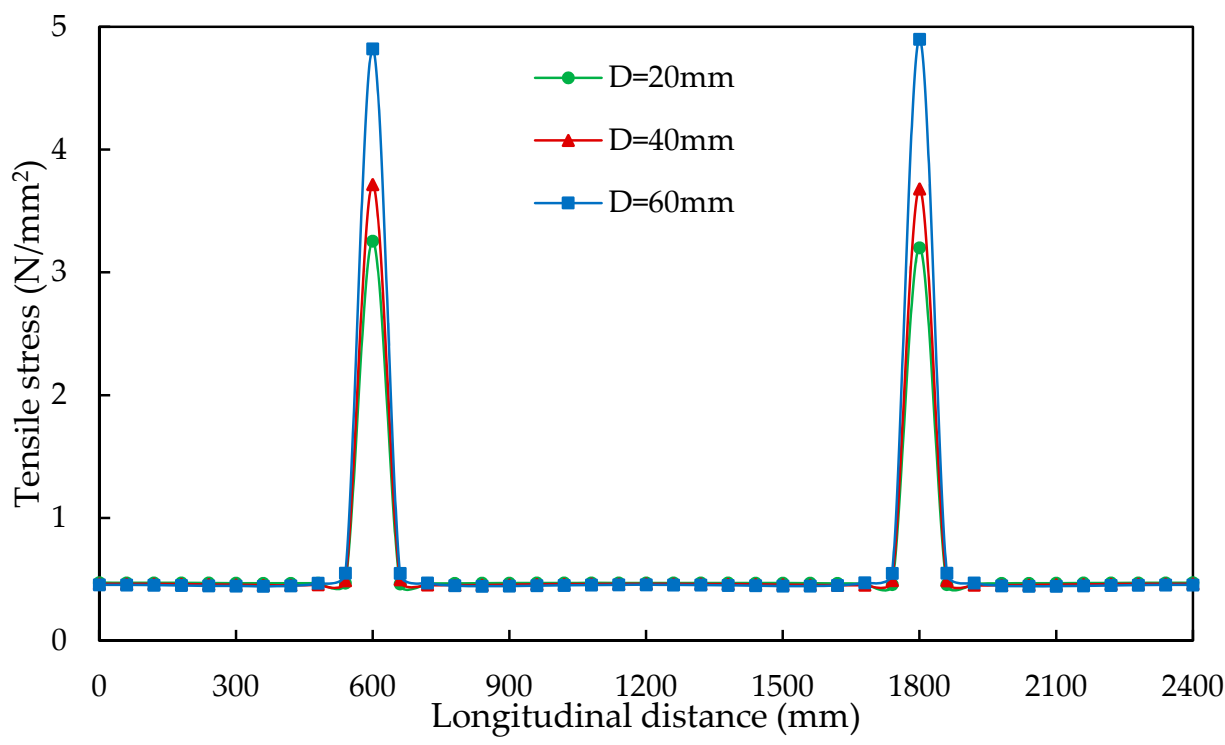

Figure 11. Comparison of maximum concrete tensile stress over the saw-cut tips along the length of concrete slab for different saw-cut depths.

The 3rd longitudinal steel bar from the outer end of the concrete slab just ahead of sawcut tips is selected for comparison purposes. The development of maximum stress along the length of the steel bar for each saw-cut depth is depicted in Figure 12. As expected, the deeper saw-cut induces the largest maximum steel stress exactly over the saw-cut tips where the concrete tensile stress is maximum in comparison to the rest of the bar length. It 
may translate that the deeper the cut-depth, the larger the concrete tensile stress, and the greater the incidence of cracking. These findings compare well with the field observation of crack developments on the CRCP sections of the Motorway E31 [12,22]. Therefore, it can be expected that the application of deeper saw-cuts could effectively serve the original intention of the active crack control method for CRCP to induce cracks from the designated locations (saw-cut tips) of the concrete slab. This may lead to the elimination of randomness in an early-age crack pattern which is considered as one of the main contributing factors to the development of fatal distresses such as punch-outs and spalling in CRCP.

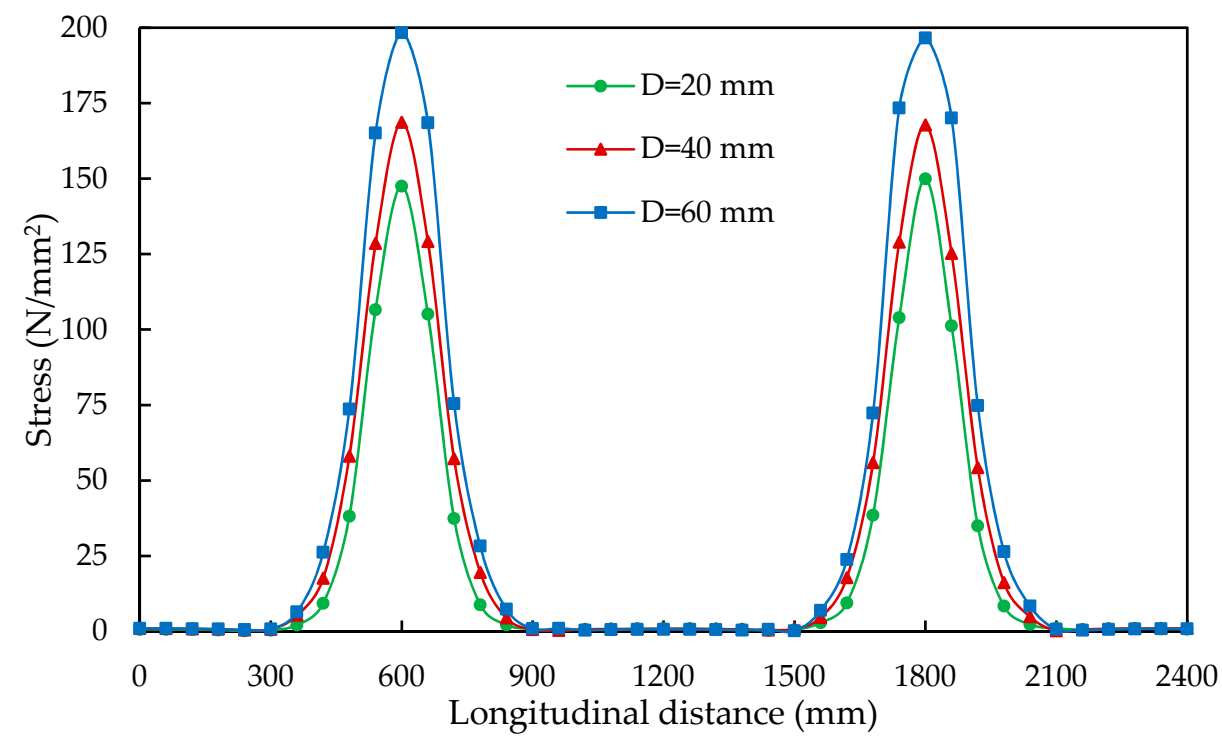

Figure 12. Comparison of maximum steel stress over along the length of the longitudinal steel bar for different saw-cut depths.

The development of crack strain over the saw-cut tips with respect to time is depicted in Figure 13. It can clearly be observed that the deeper the saw-cut depth, the larger the crack strains. This could be the possible reason that the deeper saw-cut exhibits the larger crack strain by taking an advantage of the volumetric changes to the larger depth of the concrete slab. It was also reported that the deeper saw-cut depth on the E313 section remained quite effective in inducing new cracks even in the later age of CRCP in Belgium [12,22].

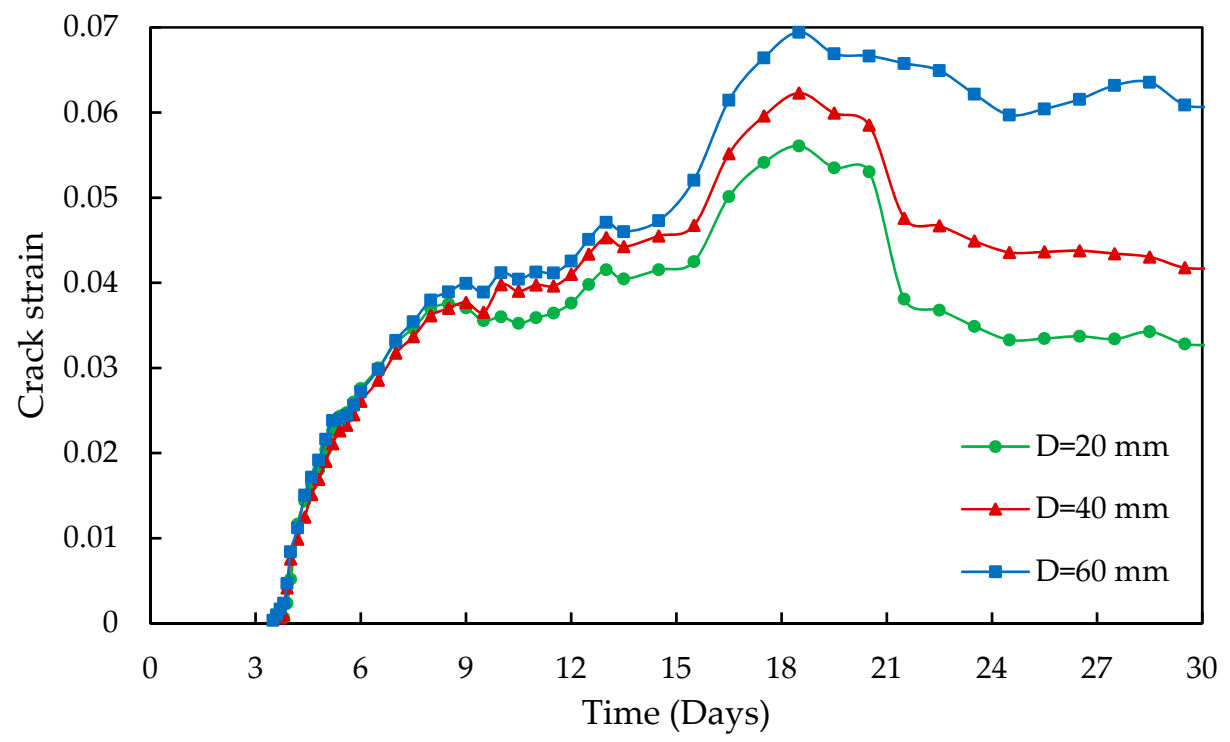

Figure 13. Comparison of crack strain over saw-cut tips for different saw-cut depths. 


\subsection{Effect of Saw-Cut Length on Early-Age Crack Induction}

Based on field observations and above discussed FE results, the deeper saw-cut is more effective than the shallower saw-cut for inducing cracks over the desired locations in CRCP. Therefore, for the deeper saw-cut depth, three different cut-lengths as illustrated in Table 6 are taken into account. Crack induction from the saw-cut tips in terms of maximum concrete tensile stress and crack strains is evaluated with respect to the type of saw-cut based on cut-length.

Table 6. Type of saw-cut based on cut-length.

\begin{tabular}{ccccc}
\hline No. & Saw-Cut Type & Depth, D $(\mathbf{m m})$ & Length, L $(\mathbf{m m})$ & Width $\mathbf{( m m )}$ \\
\hline 1 & Shorter & 60 & 200 & 4 \\
2 & Conventional & 60 & 400 & 4 \\
3 & Longer & 60 & 600 & 4 \\
\hline
\end{tabular}

The shorter saw-cut exhibits the largest maximum tensile stress over the saw-cut tips than the conventional and longer saw-cut as illustrated in Figure 14. As per boundary conditions applied in the development of the FE model as demonstrated in Figure 5, the outer longitudinal face of the concrete slab is allowed to freely expand and contract under the prevailing external temperature field which meant to cause large volumetric changes in the outer part of the concrete slab with respect to the rest of slab. Therefore, the tips of longer saw-cut could not effectively take advantage of the large volumetric changes in the outer region of the concrete slab. This could be the possible reason for the lowest values of tensile stress from the tips of longer saw-cut in comparison to those of shorter saw-cut and conventional saw-cut.

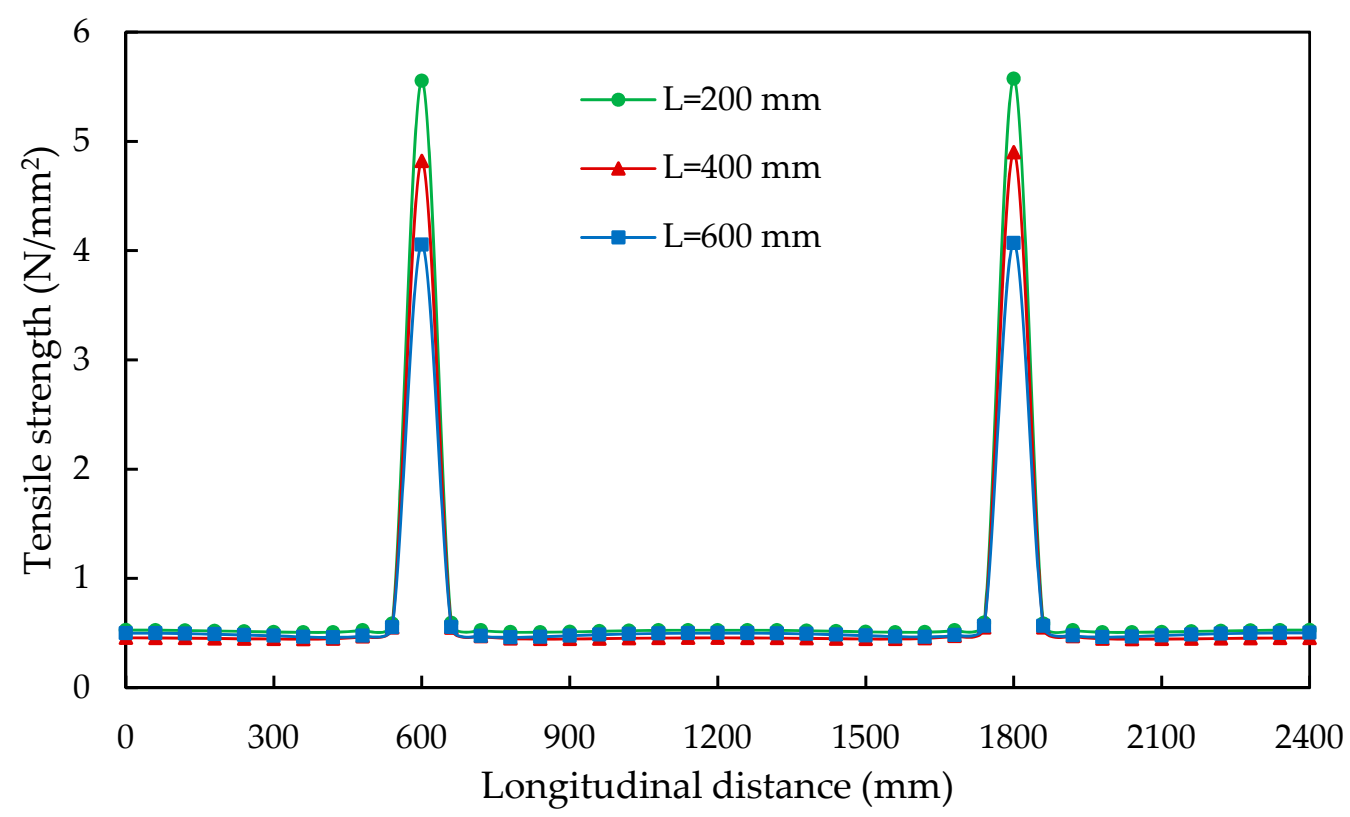

Figure 14. Comparison of maximum concrete tensile stress over the saw-cut tips along the length of concrete slab for different saw-cut lengths.

However, the development of maximum steel stress in the 3rd longitudinal steel bar demonstrated in Figure 15 shows that the longer saw-cut could be a more effective attempt for initiating the greater cracking incidence which will ultimately lead to the development of the regular spaced crack pattern. The possible reason for this could be that the longersaw-cut takes advantage of significant volumetric changes to a larger length that result in larger stress in longitudinal steel bars. However, the potential risk of steel corrosion would be significantly increased when the saw-cuts will be made longer into the concrete slab. 
The crack strain variation over the saw-cut tips with respect to time is shown in Figure 16. Being closer to the outer concrete slab face as per boundary conditions, the tips of shorter saw-cut experiences larger crack strains than those of conventional and longer saw-cut.

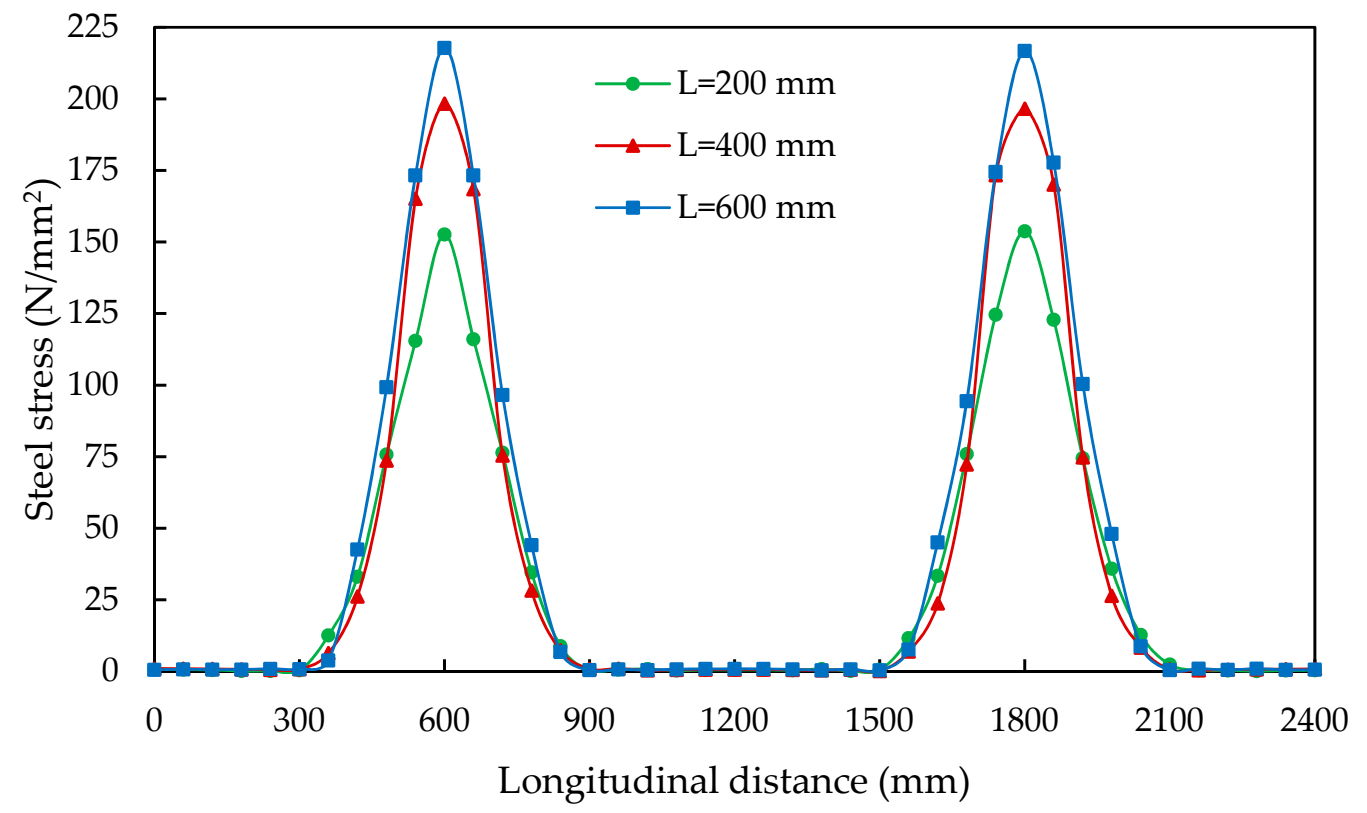

Figure 15. Comparison of maximum steel stress over along the length of the longitudinal steel bar for different saw-cut lengths.

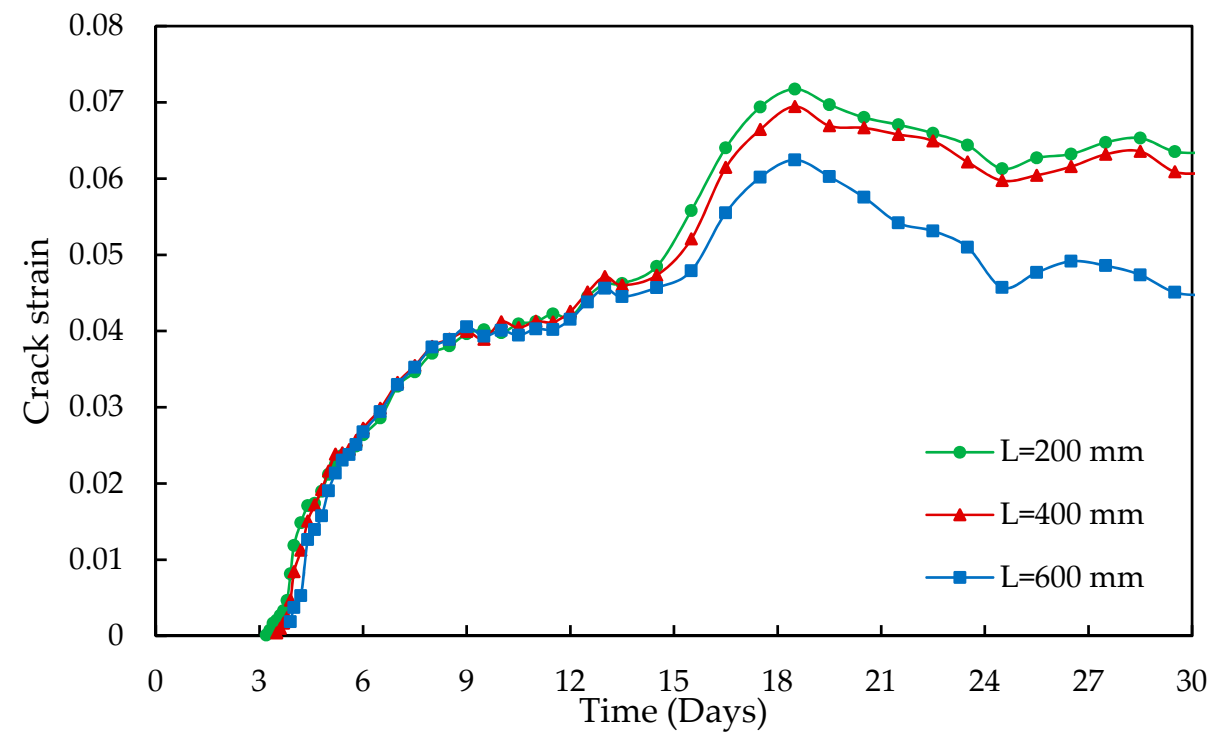

Figure 16. Comparison of crack strain over saw-cut tips for different saw-cut lengths.

Previous studies on the fatal distress in CRCP showed that most of the punch-out distress occurs in the outer lane of pavement slab [12,18,27,29,38,39,45,46]. It has also been reported that the randomness (the presence of closely spaced and divided cracks) in the transverse crack pattern increases the potential risk of punch-outs development in CRCPs $[11,12,16,47,48]$. Therefore, the adoption of deeper saw-cuts with longer cut-length for CRCP could be an effective method to minimize the randomness in the transverse crack pattern. 


\section{Discussion}

It is important to summarize the development of the solution for CRCP in the light of major benchmark studies done in the past to understand the adequacy of the solution. In the United States, different state agencies conducted comprehensive field investigations for evaluating the cracking characteristics of in-service CRCP sections $[10,17,19,49]$. It was reported that the cluster crack formation and the crack randomness could not be effectively eliminated by modifying the design parameters and construction practices. The passively induced crack pattern often led to the development of cluster cracks, Y-cracks, and divided cracks. Field findings indicated that approximately $90 \%$ of all punch-outs on CRCP sections were triggered by clusters of closely spaced cracks [45].

To eliminate the randomness in the transverse crack pattern, the active crack control method in form of shallow saw-cuts and automated tape insertions were used to induce cracks over the pre-determined locations in CRCP sections. Regular crack surveys were performed to evaluate the cracking pattern of active crack control CRCP sections. Both techniques were found quite effective in inducing more uniform crack patterns which was the original intention of the active crack control method $[8,21,50,51]$. However, there are some demerits associated with both the mentioned techniques. The tape insertion technique causes construction disruption at every insertion point, whereas the thorough saw-cut results in concrete spalling over every cut location.

While in the case of Belgium, the partial surface saw-cuts not only effectively fulfilled the purpose of the active crack control method but also eliminated the issue related to concrete spalling without any construction disruption [12,22]. The concept of partial surface saw-cuts has been numerically evaluated in this study as detailed above. The overall configuration of the CRCP structure in Belgium is not quite different from that being used in the United States and other parts of the world. Therefore, the partial surface saw-cuts instead of thorough saw-cuts and automated tape insertion could be implemented for fulfilling the main purpose of the active crack control method.

\section{Summary of Findings and Conclusions}

The standard design concept for CRCP in Belgium has been revised through several modifications regarding the amount of longitudinal steel, slab thickness, presence of asphalt interlayer, and steel depth for the purpose of eliminating the non-uniformity in the transverse crack pattern. However, CRCPs constructed following the current standard design concept exhibit the transverse crack pattern along with low mean crack spacing and a high percentage of narrowly spaced crack clusters. To induce the transverse crack over the designated locations in CRCP, the new active crack control method in form of the transverse partial surface saw-cuts was firstly adopted on the CRCP sections in the reconstruction project of the Motorway E313 in Belgium. The regular field observations have revealed that saw-cut depth significantly influences the effectiveness of early-age crack induction in CRCP.

The main purpose of the present study is to evaluate the effect of different saw-cut depths and saw-cut lengths on the early-age crack induction in CRCPs. The early-age crack induction in CRCP under the external varying temperature field condition is evaluated. The results obtained from the FE models are compared and discussed with the available field observations of crack developments on CRCP sections in Belgium. It is found that the deeper saw-cut with longer cut-lengths can significantly decrease the percentage of closely spaced cracks and clusters cracks in CRCPs. It acts as the most effective active crack control method to induce cracks over the designated locations of the concrete slab than the shallower saw-cut. This fact is also supported by the development of the largest maximum tensile stress over the tips of deeper saw-cut along the length of concrete slab. The saw-cut length also significantly influences the crack initiation and crack propagation. By increasing the saw-cut length, the stress development over the tips decreases, which may reduce the potential risk of punch-out in the outer lane of the pavement slab. 
It may be concluded that the deeper saw-cut with longer cut-lengths can be beneficial for achieving the more regular spaced crack pattern in active crack control sections of CRCP. However, preventive measures should be made to take care of the problems related the steel corrosion. In advance of costly field trials, these findings could be used as general guidelines in choosing the appropriate depth and length of the partial surface saw-cut for inducing the transverse cracks over the designated location in the CRCP pavement system. This crack induction concept for CRCP is adopted in just a few regions around the world and very limited literature is available. Therefore, more in depth experimental as well as numerical studies are needed to look into the problem to develop a more rational solution.

Author Contributions: Conceptualization, M.K.; Writing-Original draft, M.K.; Supervision, H.D.B.; Writing-Review \& editing, A.N., N.I., and P.D.W. All authors have read and agreed to the published version of the manuscript.

Funding: The funding for this research along with the Article Processing Charges (APC) have been provided by Higher Education (HEC) of Pakistan under the grant of UESTP-HRDI initiative.

Acknowledgments: In The corresponding author gratefully acknowledges financial support from Higher Education Commission (HEC), Pakistan.

Conflicts of Interest: The authors declare no conflict of interest.

\section{References}

1. Hall, K.; Dawood, D.; Vanikar, S.; Tally, R., Jr.; Cackler, T.; Correa, A.; Deem, P.; Duit, J.; Geary, G.; Gisi, A.; et al. Long-Life Concrete Pavements in Europe and Canada; The National Academies of Sciences, Engineering, and Medicine: Washington, DC, USA, 2007.

2. Kohler, E.; Roesler, J. Crack width determination in continuously reinforced concrete pavements. In Proceedings of the Second International Conference on Accelerated Pavement Testing, Minneapolis, MN, USA, 26 September 2004.

3. Mirsayar, M.; Zollinger, D. Factors influencing stresses and movements in continuously reinforced concrete pavements-A review. Eng. Solid Mech. 2018, 6, 67-82. [CrossRef]

4. Rasmussen, R.O.; Rogers, R.; Ferragut, T.R. Continuously reinforced concrete pavement design \& construction guidelines. In Technical Manual; Federal_Highway Administration and Concrete Reinforcing Steel Institute: Washington, DC, USA; Schaumburg, IL, USA, 2009. Available online: https://apps.itd.idaho.gov/apps/manuals/Materials/Materials\%20References/CNCAcrcp_ CRCP_Design-Const_Manual.pdf (accessed on 7 June 2020).

5. Rens, L. Continuously Reinforced Concrete-State-of-the-Art in Belgium. In Proceedings of the 11th International Symposium on Concrete Roads, Austin, TX, USA, 15 October-5 November 2010.

6. Rens, L.; Beeldens, A. The Behaviour of CRCP in Belgium: Observation and Measurement of Crack Pattern, Bond and Thermal Movement. In Proceedings of the 7th International DUT-Workshop on Design and Performance of Sustainable and Durable Concrete Pavements, Seville, Spain, 10-11 October 2010.

7. Kim, S.-M.; Cho, Y.K.; Lee, J.H. Advanced reinforced concrete pavement: Concept and design. Constr. Build. Mater. 2020, 231 , 117130. [CrossRef]

8. Kohler, E.; Roesler, J. Active crack control for continuously reinforced concrete pavements. Transp. Res. Rec. 2004, 1900, 19-29. [CrossRef]

9. Ren, D.; Houben, L.J.; Rens, L. Monitoring early-age cracking of continuously reinforced concrete pavements on the E17 at Ghent (Belgium). In Sustainable Construction Materials 2012; American Society of Civil Engineers: Reston, VA, USA, 2013 ; pp. 30-41.

10. Zollinger, D.; Buch, N.; Xin, D.; Soares, J. Performance of CRCP Volume 6-CRCP Design, Construction, and Performance; FHWA-RD97-151 Report; FHWA: Washington, DC, USA, 1998.

11. Zollinger, D.G. Investigation of Punchout Distress of Continuously Reinforced Concrete Pavement; University of Illinois at UrbanaChampaign: Champaign, IL, USA, 1990.

12. Ren, D. Optimisation of the Crack Pattern in Continuously Reinforced Concrete Pavements. Ph.D. Thesis, Technische Universiteit Delft, Delft, The Netherlands, 2015.

13. Ren, D.; Houben, L.; Rens, L. Cracking behavior of continuously reinforced concrete pavements in Belgium: Characterization of current design concept. Transp. Res. Rec. 2013, 2367, 97-106. [CrossRef]

14. Rens, L.; Winne, P.; Beeldens, A. Continuously Reinforced Concrete Pavement: New Development for a Sustainable Concept; Belgian Road Congress: Liege, Belgium, 11-13 September 2013.

15. Verhoeven, K. Cracking and corrosion in continuously reinforced concrete pavements. In Proceedings of the 5th International Conference on Concrete Pavement Design and Rehabilitation, Purdue University, West Lafayette, Indiana, 20-22 April 1993.

16. Selezneva, O.; Darter, M.; Zollinger, D.; Shoukry, S. Characterization of transverse cracking spatial variability: Use of long-term pavement performance data for continuously reinforced concrete pavement design. Transp. Res. Rec. 2003, 1849, 147-155. [CrossRef] 
17. Tayabji, S.D.; Tayabji, S.D.; Zollinger, D.G.; Vederey, J.R.; Gagnon, J.S. Performance of Continuously Reinforced Concrete Pavements, Volume III-Analysis and Evaluation of Field Test Data; Department of Transportation, FHWA-RD-94-180; FHWA: Washington, DC, USA, 1998.

18. Chen, D.-H.; Lin, H.-H.; Sun, R. Field performance evaluations of partial-depth repairs. Constr. Build. Mater. 2011, 25, 1369-1378.

19. McCullough, B.F.; Dossey, T. Considerations for high-performance concrete paving: Recommendations from 20 years of field experience in Texas. Transp. Res. Rec. 1999, 1684, 17-24. [CrossRef]

20. McCullough, B.F.; Treybig, H.J. Determining the Relationship of Variables in Deflection of Continuously-Reinforced Concrete Pavement. Highway Res. Rec. 1966, 131, 65-86.

21. McCullough, B.F.; Zollinger, D.; Dossey, T. Evaluation of the Performance of Texas Pavements Made with Different Coarse Aggregates; Center for Transportation Research, University of Texas at Austin: Austin, TX, USA, 2000.

22. Ren, D.; Houben, L.; Rens, L.; Beeldens, A. Active Crack Control for Continuously Reinforced Concrete Pavements in Belgium Through Partial Surface Notches. Transp. Res. Rec. 2014, 2456, 33-41. [CrossRef]

23. DIANA FEA BV. Diana User's Manual Release 10.3; DIANA FEA: Delft, The Netherlands, 2017.

24. De Winne, P.; de Backer, H.; Depuydt, S. Active crack control in continuously reinforced concrete pavements (CRCP). In High Tech Concrete: Where Technology and Engineering Meet; Springer: Cham, Switzerland, 2018; pp. 1389-1397.

25. Kashif, M.; De Winne, P.; Naseem, A.; Iqbal, N.; de Backer, H. Three Dimensional Finite Element Model for Active Crack Control in Continuously Reinforced Concrete Pavement. In Proceedings the 9th International Conference on Maintenance and Rehabilitation of Pavements-Mairepav9; Springer: Cham, Switzerland, 2020.

26. Al-Qadi, I.L.; Elseifi, M. Mechanism and modeling of transverse cracking development in continuously reinforced concrete pavement. Int. J. Pavement Eng. 2006, 7, 341-349. [CrossRef]

27. Choi, S.; Ha, S.; Won, M.C. Horizontal cracking of continuously reinforced concrete pavement under environmental loadings. Constr. Build. Mater. 2011, 25, 4250-4262. [CrossRef]

28. Choi, S.; Na, B.-U.; Won, M.C. Mesoscale analysis of continuously reinforced concrete pavement behavior subjected to environmental loading. Constr. Build. Mater. 2016, 112, 447-456. [CrossRef]

29. Kim, K.; Han, S.; Tia, M.; Greene, J. Optimization of parameters affecting horizontal cracking in continuously reinforced concrete pavement (CRCP). Can. J. Civil Eng. 2019, 46, 634-642. [CrossRef]

30. Byfors, J. Plain concrete at early ages. Build. Public Works Transp. Civil Eng. 1980, 3, 465.

31. Khan, A.A.; Cook, W.D.; Mitchell, D. Thermal properties and transient thermal analysis of structural members during hydration. Mater. J. 1998, 95, 293-303.

32. Morabito, P. Thermal Properties of Concrete: Variations with the Temperature and During the Hydration Phase; Department of Civil \& Mining Engineering \& Division of Structural Engineering: Milan, Italy, 2001.

33. Neville, A.M.; Brooks, J.J. Concrete Technology; Longman Scientific \& Technical England: London, UK, 1987.

34. Emanuel, J.H.; Hulsey, J.L. Prediction of the thermal coefficient of expansion of concrete. J. Proc. 1977, 74, 149-155.

35. Saeed, M.K.; Rahman, M.K.; Baluch, M.H. Early age thermal cracking of mass concrete blocks with Portland cement and ground granulated blast-furnace slag. Mag. Concr. Res. 2016, 68, 647-663. [CrossRef]

36. Glasser, F. Chemical, mineralogical and Micro-structural Changes Occurring in Hydrated Slag-Cement Blends. Mater. Sci. Concr. 1991, 52, 41-82.

37. Hendriks, M.A.; Rots, J. Finite Elements in Civil Engineering Applications. In Proceedings of the Third DIANA World Conference, Tokyo, Japan, 9-11 October 2002; CRC Press: Boca Raton, FL, USA, 2002.

38. Kim, S.-M.; Won, M.; McCullough, B.F. Numerical modeling of continuously reinforced concrete pavement subjected to environmental loads. Transp. Res. Rec. 1998, 1629, 76-89. [CrossRef]

39. Kim, S.-M.; Won, M.C. Horizontal cracking in continuously reinforced concrete pavements. Struct. J. 2004, 101, 784-791.

40. Kim, S.-M.; Won, M.C.; McCullough, B.F. Three-dimensional analysis of continuously reinforced concrete pavements. Transp. Res. Rec. 2000, 1730, 43-52. [CrossRef]

41. Narin, F.; Wiklund, O. Design of Slabs-On-Ground Regarding Shrinkage Cracking; Chalmers University of Technology: Göteborg, Sweden, 2012.

42. Faria, R.; Azenha, M.; Figueiras, J.A. Modelling of concrete at early ages: Application to an externally restrained slab. Cem. Concr. Compos. 2006, 28, 572-585. [CrossRef]

43. Sofi, M.; Lumantarna, E.; Mendis, P.; Zhong, A. Thermal Stresses of Concrete at Early Ages. J. Mater. Civil Eng. 2019, $31,04019056$. [CrossRef]

44. Sofi, M.; Mendis, P.; Baweja, D.; Mak, S. Influence of ambient temperature on early age concrete behaviour of anchorage zones. Constr. Build. Mater. 2014, 53, 1-12. [CrossRef]

45. Chorzepa, M.G.; Johnson, C.; Durham, S.; Kim, S.S. Forensic Investigation of Continuously Reinforced Concrete Pavements in Fair and Poor Condition. J. Perform. Constr. Facil. 2018, 32, 04018031. [CrossRef]

46. Ryu, S.W.; Choi, P.; Choi, S.; Won, M.C. Improvements of Full-Depth Repair Practices for Distresses in Continuously Reinforced Concrete Pavement. Transp. Res. Rec. 2013, 2368, 102-113. [CrossRef]

47. Suh, Y.-C.; Hankins, K.D.; McCullough, B.F. Early-Age Behavior of Continuously Reinforced Concrete Pavement and Calibration of the Failure Prediction Model in the CRCP-7 Program; Center for Transportation Research, Bureau of Engineering Research: Austin, TX, USA, 1992. 
48. Suh, Y.-C.; McCullough, B.F.; Hankins, K.D. Development and application of randomness index for continuously reinforced concrete pavement. Transp. Res. Rec. 1991, 1307, 136-142.

49. Tsai, Y.J.; Wang, Z. Critical Assessment of I-85 CRCP Crack Spacing Patterns and Their Implications for Long-Term Performance; Georgia Department of Transportation, Office of Research: Tbilisi, Georgia, 2014.

50. Kohler, E.; Long, G.; Roesler, J. Construction of Extended Life Continuously Reinforced Concrete Pavements at ATREL; Illinois Dept. of Transportation, Bureau of Materials and Physical Research: Springfield, IL, USA, 2002.

51. Zollinger, D.G.; Soares, J. Performance of Continuously Reinforced Concrete Pavements, Volume VII-Summary; Department of Transportation, FHWA-RD-98-102; FHWA: Washington, DC, USA, 1999. 